\title{
EL SON DE NEGRO UN DISEÑO DE INTEGRACIÓN CURRICULAR PARA SANTA LUCÍA ATLÁNTICO Y LA SUBREGIÓN CANAL DEL DIQUE EN EL CARIBE COLOMBIANO
}

\author{
THE "SON DE NEGRO": A DESIGN OF CURRICULAR INTEGRATION FOR \\ SANTA LUCIA, ATLANTICO AND THE SUBREGION CANAL DEL DIQUE IN \\ THE COLOMBIAN CARIBBEAN
}

Por: : Manuel Antonio Pérez Herrera ${ }^{1}$

Recibido: 26 de abril de 2019 - Aprobado: 23 de octubre 2019

Son de negro, un diseño curricular que integra las prácticas y saberes populares de la cotidianidad a la educación en el municipio Santa Lucia -

Atlántico (Pérez, 2006).

\section{RESUMEN}

"El Son de Negro", constituido en diseño de integración curricular es el resultado de un proceso de búsqueda de nuevas prácticas y saberes inculturada en la cultura ancestral Son de Negro, contexto visibilizado como problema educativo-formativo en la localidad de Santa Lucia y su área de influencia. En el estudio igualmente se devela el camino creativo inspirado por lo investigado para darle estructura a una actividad curricular acompañado metodológicamente por la revisión documentada, el trabajo de campo, grupo focal y talleres de socialización. Al mismo tiempo, se entrelazan los aspectos relacionados con los componentes del "diseño curricular de integración", haciendo una distintiva contextualización en el municipio de Santa Lucía y la Zona del Canal del Dique, a partir del conocimiento de los lenguajes de la música, la danza, los ritmos, la narrativa de los versos, los bailes, parafernalias y demás factores representativos de esta cultura ancestral del Caribe colombiano.

El trabajo investigativo que se presenta está fundamentado en una didáctica constructivista alternativa que se desprende de la investigación, dado que daría a los estudiantes, docentes y comunidad la oportunidad de fomentar la conciencia del sentido de identidad y trabajar en forma integrada para resolver desde la escuela problemas del contexto.

\footnotetext{
${ }^{1}$ Doctor en Ciencias de la Educación, Universidad de Caldas, Manizales, RUDECOLOMBIA; licenciado en Educación Musical; Especialista en Evaluación Educativa; Magister en Educación y Cognición; Becario en doble titulación doctoral, Universidad de Granada España. Músico Profesional. Productor musical y documentalista. Escritor en temas de didáctica, curriculum, pedagogía, educación social, estudios de folclor Caribe. Profesor titular e investigador de tiempo completo de la Universidad del Atlántico manuelperez@mail.uniatlantico.edu.co
} 
Palabras clave: Son de Negro, integración curricular, procesos educativos, investigación formativa.

\begin{abstract}
"El Son de Negro", a design of curricular integration, is the result of a process of searching for new practices and knowledge enculturated in the ancestral culture "Son de Negro\#, context visible as an educational-formative problem in the town of Santa Lucia and its area of influence. The study also unveils the creative path inspired for the research outputs to give structure to a curricular activity together with the documented review, fieldwork, focus group and socialization workshops, from the methodological standpoint. At the same time, aspects related to the components of the "curricular design of integration" are intertwined, making a distinctive contextualization in the Municipality of Santa Lucia and the Canal del Dique Zone, based on the knowledge of the languages of music, the dance, the rhythms, the narrative of the verses, the dances, paraphernalia and other factors representative of this ancestral culture of the Colombian Caribbean.
\end{abstract}

The research work presented is grounded on an alternative constructivist didactic that emerges from the research, given that it would give students, teachers and community the opportunity to promote awareness of the sense of identity and to work in an integrated way to solve context problems since the school period.

Keywords: "Son de Negro", Curriculum integration, Educational processes, formative research.

\title{
INTRODUCCIÓN
}

El Son de Negro es una manifestación que tiene su arraigo en las comunidades de la Zona del Canal del Dique, es una expresión ancestral la cual los pobladores de comunidades negra de esta subregión del Caribe colombiano la ejercitan como bien público, es decir, espacio de participación y de libre formación, de construcción de prácticas y saberes populares, no obstante, el autor de esta propuesta, tantos los imaginarios, personajes, el geocontexto y la multiplicidad de lenguajes que emergen de esta expresión de la tradición oral la constituye en una didáctica constructivista alternativa con énfasis en disciplina de acción social, de cambio, de intervención y transformación de múltiples situaciones y tipos de desarrollo" (Caride, 2005).

En este estudio de integración curricular se parte del hecho de insertar a los procesos educativos de Santa Lucia y la subregión del Canal del Dique, el ligado social y cultural de esta manifestación artística, no obstante que la historia y el arte desde principio de la humanidad se develan como dos caracteres poderoso de la existencia humana (Ortega \& Gasset, en Gutiérrez Constantino, 2003). En consecuencia, la integración de las prácticas y saberes producto del Son de Negro, se constituye en un nuevo sistema de mediación social y educativa, que tiene como eje central desentrañar el arte y la historia de este acervo sociocultural inculturado en las vidas de las comunidades desde finales del siglo XVII. En síntesis, el Son de Negro es un compendio de lenguajes artísticos, estéticos, sociales, etc., que ejercitados en el tiempo por los hombres y mujeres asentados en la 
subregión Canal del Dique.

En atención al anterior acápite, el quehacer educativo que se pretende desde la activación de los elementos del Son de Negro, se hará uso consciente de la didáctica constructivista alternativa, como disciplina expedita para jalonar nuevas prácticas y saberes mediados por la cultura popular, además de constituir formas de transmisión para que perdure en el tiempo, de esta manera se busca mantener la coherencia en un diseño curricular que integra contenidos seleccionados y organizados para una práctica educativa que conecta saberes científico con saberes del contexto, en consecuencia, en el trabajo metodológico confluyen medios cualitativos, técnicas e instrumentos como las visitas de campo, el diario de notas, la observación dirigida - participante, diálogos en comunidad, etc., todo esto convidan a lograr la orientación de procesos formativos coherente con las necesidades, valores e intereses de la comunidad objeto de beneficio.

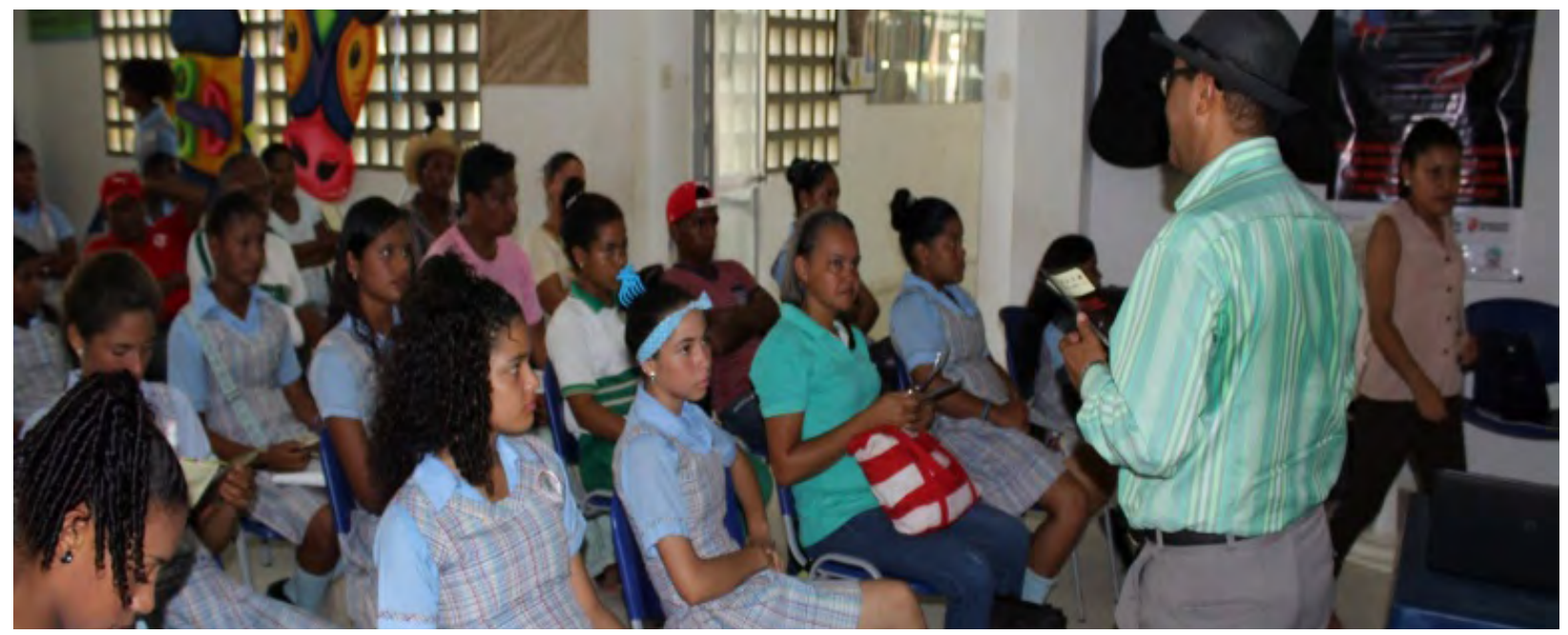

Foto $N^{\circ} 1$. Socialización de la propuesta de diseño curricular con la comunidad educativa de Santa Lucía (Fotografía del articulista).

El estudio de la cultura de la tradición Son de Negro, igual que otras expresiones culturales peculiares, se constituirá para este diseño curricular en eje de desarrollo científico, social y además generador de espacios académicos en los que se le vaya dando cuerpo al conjunto de conocimientos adquiridos a través de la práctica de sus elementos constitutivos desde un ámbito especializado del mismo. En ese sentido, se trata de identificar y comprometer a quienes se animan a emprender esta nueva ruta de aprendizaje y este debate epistemológico a realizar nuevas construcciones teóricas y prácticas sociales. Comprometerlos a centrar la formación, la intervención y accionar de las actividades propias de las comunidades como andamiaje genérico de nueva construcción pedagógica" (Quintana, 1976).

En tal sentido, para la implementación del diseño curricular Son de Negro, es indispensable contar con un centro de acopio provisto de los recursos necesarios para la indagación y la formación investigativa, igualmente la realización de seminarios y talleres de socialización con la comunidad 
educativa, cuyo propósito es dar a conocer la planeación, gestión y sistema didáctico y metodológico a utilizar en la orientación de la propuesta que se presenta, solo así se podrá interpretar, comprender y resignificar necesidades, valores, acciones y actuaciones de la cotidianidad, desde diversos ámbitos educativos, sociales y culturales. Dando cuenta de las construcciones sociales, educativas, económicas, culturales, artísticas, entre otros, que con la activación de los activos artísticos con el Son de Negro, factores estos que de alguna manera inciden en la calidad de vida de las comunidades y por ende, develar las mediaciones fundamentales implicadas en la formación de la conciencia social-racional ciudadana desde el contexto educativo al entrar en contacto con este nuevo sistema de prácticas y saberes en la educación contemporánea.

En consonancia con lo anterior, la investigación formativa en este diseño curricular se presenta como eje transversal de los procesos educativo que es en sí un sistema de desarrollo humano y formación integral, cuya tendencia investigativa se erige como factor articulador de la producción de nuevos saberes, de trasformación de necesidades y valores, de accionar creativo, espiritual, emocional e intelectual de los constructores sociales desde sus contextos vitales, es por eso, que en el tránsito de la nueva práctica educativa la investigación formativa en el contexto social media como disciplina teórico-práctica-vivencial, que busca establecer el cómo, el por qué y el para qué: ¿formar estudiantes hacia el desarrollo consciente de la cultura del contexto desde una educación de integración social?

En consonancia con lo anterior, se infiere que en este proceso de formación investigativa de saberes sociales, las práctica populares como las que ejercitan tanto actores como hacedores de Son de Negro en la Región del Canal del Dique, son activos naturales establecidos en contenidos y fuente pedagógica para el currículo, lo cual se consolida desde el momento en que se procede a realizar diagnóstico de necesidades y valores, $\mathrm{y}$, es en ese proceso de búsqueda en donde surgen nuevas construcciones y formas discursivas, contenidos, prácticas vivenciales, estructuras, diseños y demás elementos, que proporcionalmente consolidan el abordaje pedagógico dinamizado desde la didáctica constructivista alternativa propuesta en este estudio..

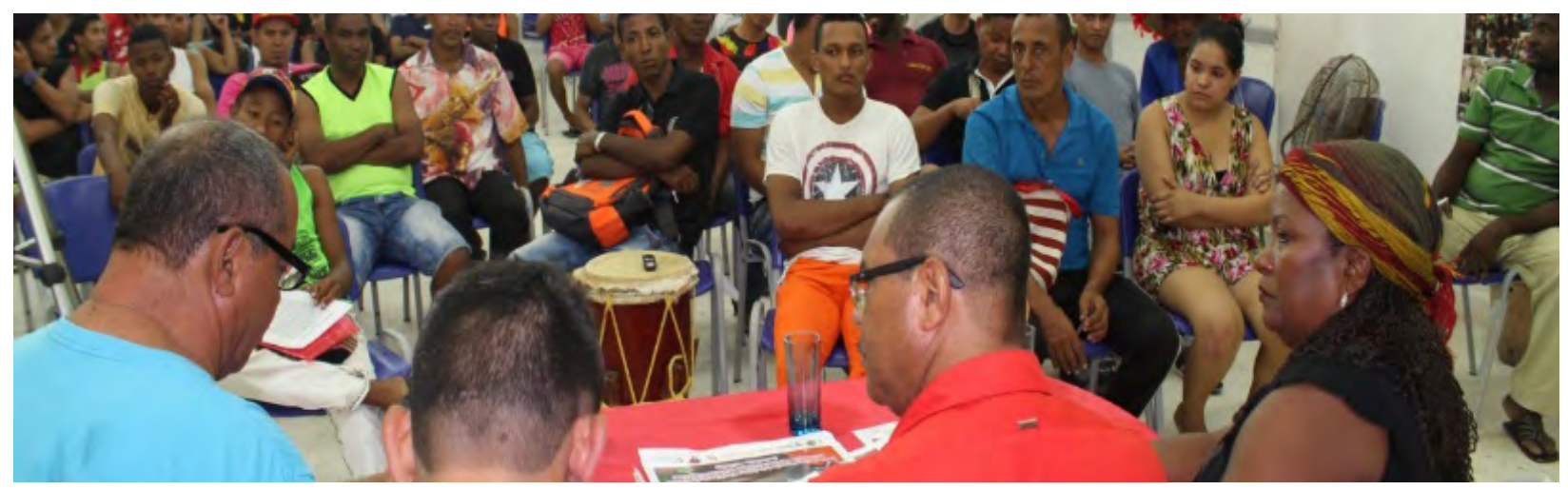

Imagen $\mathrm{N}^{\circ}$ 2. Diálogos abiertos con la comunidad del Canal del Dique en el Festival Son de Negro, Santa Lucia, junio 2018. (Fotografia del articulista). 
Integrar los saberes y prácticas inculturadas en la expresión artística Son de Negro al currículo, de hecho está contribuyendo al desarrollo de la identidad cultural en Santa Lucía y sus áreas de influencia, y al mismo modo se le apuesta a desterrar de los currículos las desigualdades sociales manifestadas en sus estructuras y contenidos, lo cual evidencia la falta de coherencia e identidad en la selección y organización de la cultura del contexto, situación problémica que es productora de desequilibrio y falta de equidad en el desarrollo normal de un proceso político compendiado en el Estado Social de Derecho (Constitución Política de Colombia, 1991, art.1.), donde la distribución de recursos para este tipo de proceso social, en parte lo que prima es la negativa del reconocimiento de los múltiples desarrollo que de manera práctica logra la comunidad al entrar en contacto con la diversidad cultural de los contextos, por eso la exigencia permanente que se le hacen a las instituciones gubernamentales para que propicien la participación democrática, a través de la asignación de recursos económicos y espacios de participación educativa y cultural a los sectores populares, y acabar así con la distribución desigual de la economía establecidas en políticas públicas y de Estado (Cepal, Gett Rosenthal, 1992, p.102).

Por otro lado, se resalta en este apartado, por ejemplo: En el caso concreto de la investigación etnoeducativa, que aunque la normatividad universal en derechos humanos, reconoce los derechos étnicos y culturales, también es cierto que en Colombia quienes rigen los destinos de la nación y concretamente los sistemas educativos, no contextualizan en los currículos de las instituciones educativas los activos culturales locales-regionales como apertura a la participación democrática integradora de procesos educativos sociales que visibilice las experiencias de (sabedores y transmisores de esta tradición oral), brindándoles las oportunidades del desarrollo libre de la cultura popular y ciudadana, $\mathrm{y}$, por el contrario en esos administradores educativos es notorio el flujo mental inconsciente e inconsecuente de la negativa de cambio de actitud y de apertura al desarrollo integral comunitario en aras de enfocar la práctica y la formación de la sociedad de manera integrativa.

De la anterior posición se devela como un avance y/o apertura de favorecimiento a la dignificación de la cultura del contexto Son de Negro y de la labor del docente comprometido, ese que es capaz de contribuir al logro de los ideales comunitarios, como los de la escuela y del estudiantado. De esta forma se podría actuar acorde con las exigencias del nuevo siglo en cuanto a la globalización del conocimiento, las nuevas tecnologías, la competitividad y la modernidad del currículum. De hecho, para Magendzo, la relación entre el currículum y la sociedad ha sido y será una preocupación permanente de la educación y de los diseñadores del mismo. De aquí, que no es aventurado decir que existe una "historia social de la educación y el currículum" que identifica los cambios que ha sufrido la relación educación y sociedad en el transcurso del tiempo. Se podría decir, que el sentido primigenio de la educación, en especial de la educación pública, ha sido el otorgamiento de su significado social. "Una historia de esta naturaleza introduce la trama que existe entre el control, el poder y el conocimiento; que adquiere una ineludible dimensión histórica y política de país" (Magendzo, 2003, pág. 13). 
En Colombia, López (2002, pág.52); parafraseando a Magendzo (1991), desde el Programa Interdisciplinario de Investigación en Educación, PIIE, considera que "la planificación curricular en América Latina en su mayoría es centralizada"... Expresa que existe una tendencia marcada a tomar decisiones desde el gobierno central, que afectan significativamente a las regiones y localidades e ignoran los desarrollos propios de los contextos regionales y locales y generan un desfase entre los programas y proyectos ofrecidos, lo cual va en detrimento de la atención de necesidades y valores detectados en las localidades y/o regiones, ya que muchos de los proyectos curriculares son producto de la importación de modelos, que en repetidas ocasiones responden a contextos y necesidades ajenas, cultural y socialmente, a los escenarios en donde se implantan.

La propuesta curricular propuesta por naturaleza en su diseño es interdisciplinar, el mismo da cuenta de la existencia de una cultura ancestral artística inculturada desde tiempos remotos en la localidad de Santa Lucía - Atlántico y las poblaciones ancladas a orillas del Canal del Dique en el Caribe de Colombia, y fue precisamente en esos espacios antropológicos y sociales donde se indaga el problema de descontextualización que tienen los currículos educativos desprendidos de la cultura del contexto. No obstante, fue importante realizar un recorrido acucioso por propuestas, programas, planes de estudios y diseños curriculares en las localidades, trabajo de intervención, análisis e interpretación mediado por la revisión documentada, la observación dirigida y participante, el análisis de contenidos en documentos escritos, documentales (audiovisuales) y encuentro con la comunidad educativa de Santa Lucía. Luego la información recabada fue sistematizada e interpretada y la misma fundamentó el estado del arte del estudio, del mismo modo se da cuenta de cómo fueron emergiendo supuestos teóricos y conceptuales sólidos, que concretizan la fundamentación de la didáctica constructivista alternativa propuesta y el enfoque metodológico de la estructuración e implementación del diseño curricular.

En la estructuración de la propuesta se tuvo en cuenta la participación activa de la comunidad en pleno (Ortega \& Gasset, 1972), uno de los fundamentos sólidos del diseño tiene que ver con factores normativos tanto a nivel nacional como internacional, de esa manera se pudo determinar las implicaciones que confluyen en los argumentos que se presentan. Igualmente, los vestigios de estructuras y diseños curriculares que dan cuenta de cómo desde principios de la humanidad, el hombre no solo se vislumbra como expresión creadora de cultura, sino, también como constructor y productor que siempre ha sido, pero que infortunadamente "su creación intelectual es utilizada por los entes de reconocimiento científico de manera utilitaria, anteponiéndole a sus principios humanísticos ideologías reduccionista de lo humano y de su medio natural” (Berger y Luckmann, 2006).

La construcción del diseño curricular Son de Negro, será dinamizado y orientado teniendo en cuenta los principios de la Cátedra Afrocolombiana, lo cual encaja coherentemente en la integración curricular de los sistemas educativos del municipio de Santa Lucía, ya que en su orden lo que se pretende es la búsqueda de nuevos conocimiento sobre la música, la danza, la literatura, la oralidad, 
los accesorios, atuendos, parafernalias, símbolos y demás representaciones con que se manifiesta la cultura ancestral son de negro, como vestigios inmediatos del hombre del Canal del Dique que es constructor de prácticas, saberes y formas de vida, él vive en un mundo que ha idealizado y se envuelve en sus cosmovisiones, y de esa forma logra el entretejer social de un conocimiento pluralista e integrador (Pérez, 2006, pág. 12).

En consonancia con el anterior enunciado, el estudio parte del hecho que el hombre de la subregión Canal del Dique, es un sujeto de creación activa quien desde tiempos remoto ha logrado dinamizar sus expresiones tradicionales al tiempo que ha sido capaz de comprender los atributos culturales con los cuales ha vivido en el tiempo. Lo expresado, ha sido común en esta gran subregión del Caribe en donde tanto hombres como mujeres ejercen el rol de artistas innatos, intérpretes, hacedores y transmisores de prácticas y saberes propios de la cotidianidad, mediados por la música, la danza, la literatura popular de los versos narrativos de las canciones y con estilo costumbristas, es decir, todo este andamiaje artístico-cultural se constituye en una construcción sociocultural del hombre del Dique desde el mundo de la vida. Lo anterior refrenda el supuesto que: "El arte, desde el principio de la humanidad, ha sido el foco más importante por medio del cual se ha podido diferenciar cada una de las culturas y épocas de la civilización" (Rosenthal, 1991), las culturas permiten que se aprenda de ellas, ya que "el espíritu de los pueblos se resume en el bagaje simbólico que se conserva en el pensamiento, la tradición oral, formas de convivencia, en la religión, en el quehacer científico, social, tecnológicas y artísticas” (Rosenthal, 1991, pág. 257). Todo este soporte teórico y reflexivo, sirvió de insumos para fundamentar la propuesta objeto de estudio y otras encaminadas a la integración de estudios socioculturales-etnoeducativos-interculturales, etc., a las instituciones educativas de la región Caribe de Colombia, orientada como alternativa de cambio.

En este ámbito discursivo-problémico, por diversos factores históricos, ideológicos, políticos, culturales, sociales, institucionales, administrativos y económicos, en la región Caribe colombiana, es imperatorio muchas veces avanzar hacia la inclusión de estudios etnoeducativos en las instituciones educativas para que la cultura del contexto y la cultura mundo tengan puntos de encuentro en los currículos institucionales. En consecuencia a partir de los diagnósticos realizados en las instituciones educativas de Santa Lucía, se pudo conocer que en los sistemas educativos de la localidad no se han integrado propuestas educativas como la que se presenta, la cual busca que se involucren a estudiantes, actores-hacedores-educadores y el contexto social, para que en un mismo espacio transdisciplinariamente se logre el fomento del conocimiento de una cultura ancestral inculturada en la diversidad étnica, histórica y cultural de la región Caribe, sistema de prácticas y saberes que será mediado por la organización transversal de contenidos para un nueva forma de educar para la vida.

Desde el la integración de los estudios sobre el Son de Negro, se propende por una educación integradora de la cultura del contexto como fuente pedagógica, y a su vez visibilizar esta manifestación 
artística como constructo promisorio de comunicación de lenguajes artísticos, discursivos, comunicativos, etc, concebidos como área esencial de una educación flexible que se abre como espacio de construcción de nuevo tejido social capacitado para la comprensión del entendimiento humano y de conocimiento holístico, al tiempo de formar ciudadanos que logren desde sus nuevas prácticas impactar significativamente los tipos de desarrollo que se logren en la cotidianidad, al tiempo de conjugar una formación eficiente, eficaz y placentera en la comunidad educativa. Por otro lado, con la implementación de este diseño de integración se le está apostando a la identificación y valoración de los elementos artísticos, la creatividad, la inteligencia musical, la espiritualidad del hombre del Canal del Dique, la conciencia artística, la emotividad, la sensoriomotricidad educativa de Santa Lucía y el Caribe colombiano, propuesta que como alternativa de cambio se preocupa por el reconocimiento de los imaginarios de poblaciones y grupos étnicos, hoy estudiados y constituidos en perspectiva teórica-discursiva generadora de nuevos conocimiento el cual tiene su génesis en el saber popular de los contextos reales.

La complejidad de los lenguajes artísticos a desarrollar prioriza la búsqueda de la creación social, y de estructuras cognitivas, afectivas, emocionales, espirituales, psicológicas, metacognitivas, pensamiento crítico, etc., en los contextos objetos de estudio, donde la intencionalidad académica justifique el por qué y para qué del sistemas educativo que se lleva a cabo, el cual debe estar en consonancia con los marcos jurídicos y normativos de la educación colombiana y de organismos internacionales que le apuestan al desarrollo de una educación integradora de lo humano, lo social, lo artístico y científico (Unesco, 2017), en los enfoques teóricos: (diseños curriculares, investigativos, formativos, psicológicos, valorativos, prácticas educativas), etc., haciendo posible la integración de los saberes populares de los contextos al ponerlos a dialogar con los códigos elaborados, es decir, el conocimiento científico, mediados por un clima de concertación, convergencia social, democratización y colaboración entre la institución, los docentes, los estudiantes y la comunidad objeto de beneficio y sus área de influencia social y geográfica.

En consecuencia, nos ponemos a tono con la tarea que hoy se emprende en la búsqueda y transformación de los problemas que históricamente presenta la inclusión de los estudios multiculturales en la región Caribe, desde los diversos niveles educativo. Por ello en el diseño que se presenta la importancia de visibilizar y reflexionar comprensivamente sobre aquellas fuentes y factores que se han constituido en obstáculos y que han impedido integrar los saberes populares a estructuras curriculares de programas académicos. Situación conocida en los programas diagnosticados en la localidad de Santa Lucía, como en programas magisteriales en el Departamento del Atlántico, el Distrito de Barranquilla, lo cual no es ajeno en otras regiones de colombiana, donde en muchas de las currículas se observan diferencias en la organización de los contenidos, donde es nula la cultura del contexto, y más bien prima la formación profesional de prácticas codificadas ancladas en la cientificidad, lo que en relación a nuestra propuesta, se pierde así la coherencia respecto a la construcción de estructuras y diseños curriculares contextualizados, visionario del carácter pluriétnico, 
multicultural e intercultural, de región-nación (Pérez, 2009, pág. 8).

En esta elaboración curricular según lo expresa la comunidad docente de Santa Lucía, aduce que su participación al igual que la estudiantil en materia de orientación de procesos de formación que integren contenidos de la cultura ancestral Son de Negro ha sido nula, y que en las elaboraciones de textos, materiales y de recursos didácticos que ellos realizan responden a parámetros y criterios diferentes a los requeridos para una población culturalmente diversa a la de Sana Lucía y en particular, a las aspiraciones de estudiantes de comunidades negras e indígenas específicas de la región Caribe. En términos generales, la mayoría de las decisiones en cuanto a la fundamentación teórica-conceptual, a contenidos, objetivos, etc., los currículos están refrendados en posiciones inconexas, trabajadas por expertos o especialistas en elaboraciones de mallas curriculares y planeación educativa y de otros menesteres recomendados por las casas editoriales nacionales y de ámbito internacional, sin ningún vínculo y sin conocimiento de la idiosincrasia de los contextos, en síntesis, estos currículos, adolecen de la inclusión de la diversidad del país (Pérez, 2010).

Qué diferente sería si los sistemas educativos, los entes institucionales que dirigen los sistemas educativos, al igual que los directivos docentes, pongan en circulación los principios de la nueva Constitución Política de Colombia de 199 y la expedición de la Ley 70 de 1993, o ley de negritudes, las que en sus contenidos trazan la hoja de ruta para hacer de Colombia un país respetuoso de su diversidad, a partir de reconocerse como una nación pluriétnica y multicultural. El artículo $7^{\circ}$ dice: "el Estado reconoce y protege la diversidad étnica y cultural de la nación colombiana", por su parte en el artículo $13^{\circ}$ se expresa que: "El Estado promoverá las condiciones para que la igualdad sea real y efectiva y adoptará medidas a favor de los grupos discriminados y marginados" (Constitución Política de Colombia, 1991). Consecuente con este mandato, el legislativo incluye en la Ley General de la Educación (Ley 115 de 1994), en el título III, modalidades de atención a poblaciones y en el capítulo 3, lo referente a la educación para grupos étnicos, en este acápite se define qué se entiende por educación para grupos étnicos, sus principios y fines, la formación de educadores para grupos étnicos y otras normas de interés (Ley 115 de 1994). Posteriormente, el Estado reglamenta la atención educativa para grupos étnicos, con la aprobación del Decreto 804 de 1995, donde el artículo $1^{\circ}$ manifiesta que: "la educación para grupos étnicos hace parte del servicio público educativo y se sustenta en un compromiso de elaboración colectiva, para que los distintos miembros de la comunidad en general intercambien saberes y vivencias con miras a mantener, recrear y desarrollar un proyecto global de vida de acuerdo con su cultura, su lengua, sus tradiciones y sus fueros propios y autóctonos" (Decreto 804 de 1995).

En ese mismo orden normativo, en la resolución sobre indicadores de logros, el Ministerio de Educación incluye algunos apartes significantes que si bien es cierto no son textuales, abren horizontes de posibilidades para ser utilizados en programas con enfoques diversos. Entre otros indicadores están: "Reconoce en la superación de la barrera del idioma, un facilitador del proceso de interculturalidad 
que se evidencia cuando desarrolla actividades socio-culturales, manifiesta intereses particulares, hace proyecciones laborales y profesionales" (Resolución 2343 de 1996, Proceso Curriculares e Indicadores de Logros). Pérez (2012), en su tesis doctoral: Integración de la música a la estructura curricular de los programas académicos artístico-musicales de la Universidad del Atlántico. "reevalúa los patrones conceptuales, paradigmas, contenidos y formas de organización de los procesos de enseñanza-aprendizaje prescritos en la organización curricular actual de los programas de Educación Artística y Licenciatura en Música, perteneciente a la Universidad del Atlántico, buscando establecer la necesidad de integrar al currículo prácticas y saberes de la cultura del contexto camino al reconocimiento de la productividad y creación cultural de la comunidad mediada por la formación de educandos con capacidades cognitivas, con identidad socio-cultural camino al desarrollo integral en contexto (Vygotsky, 1979). Por ello, se comparte la posición critica que el aprendizaje musical y los demás lenguajes artísticos, sus caracteres son de orden interdisciplinar y por lo tanto se deben contextualizar e integrarse al currículo junto con la cultura de la cotidianidad para que no se siga restringiendo las prácticas y saberes populares en los ámbito de la enseñanza especializada anclada en modelos y diseños curriculares conservadores implantado históricamente en el sistema educativo obligatorio, lo cual riñe con los sistemas educativos de este nuevo siglo.

En consecuencia, el estudio realizado por Pérez Herrera, logra develar las diversas posturas y contribuciones que de manera interdisciplinaria se le han hecho al desarrollo curricular y a las diferentes alternativas educativas que hoy son temas de estudio y discusión, él centró la atención en resignificar una postura sociocultural desde el ámbito científico y consolidarla como disciplina de integración no dispuesta en parcelas separadas, música, artes plásticas, teatro y danza, elementos que en su devenir han sido eclipsados por la afluencia de esos modelos manufacturados y mecanicistas enclavados en contenidos cientificistas (Pérez, 2012), y otras veces por la negativa de profesores (as) y por los llamados expertos quienes muchas veces han pretendido introducirlos en sus microdiseños, alejándose así de la concepción de integración que tiene el arte en el hoy de carácter interdisciplinar - transdisciplinar y/o transversal (Stenhouse, 1997).

El gran significado axiológico que presenta la propuesta curricular expuesta, deja en claro los avances de iniciativas de construcción de sociedades más equitativas y democráticas. En armonía con los desafíos que plantea la diversidad cultural que exige comprender las diferencias como potencialidades y no como amenazas (Canclini, 1995). Pero las instituciones magisteriales y las universidades siguen haciendo este trabajo en forma aislada, guiado por intereses individuales y/o burocráticos, en virtud de lo cual no existen políticas que articulen estos procesos a la visión y misión magisterio-universidad. Entonces, el reto de la propuesta educativa, estriba no solo en incluir a la cultura de la tradición de comunidades ancestrales, sino que la misma busca la inclusión de todas las personas del contexto y sus área de influencia, sin distingo alguno, haciendo énfasis en formar culturalmente a todos los pobladores hombres y mujeres desde distintos niveles formativo, edad cronológica y sin distingo alguno, y juntos propiciar la transformación de la cultura ancestral 
Son de Negro, en un plan de desarrollo humano integral y de conocimiento académico multicultural (Pérez, 2016, pág. 14).

En síntesis, es importante aclarar que para que esta propuesta curricular de avanzada se realice con todas las expectativas y los llenos requeridos en una educación inclusiva, abierta al cambio, es indispensable contar con los recursos disponibles: humanos, materiales, institucionales, financieros, bibliográficos, técnicos y tecnológicos. Y por ende, que las instituciones implicadas en procesos gubernamentales, administrativos, políticos, culturales y educativos, acojan este tipo de propuesta que busca elevar la conciencia ciudadana y el sentido de pertenencia por el reconocimiento del arte, la historia, la tradición, los personajes, las músicas, danzas, bailes, artesanías, sistemas de vida, los ambientes, entre otros, como valores a transformar y su permanencia en el tiempo, esto como principio y forma de la identidad a la cual hay que apostarle según lo explicita la Constitución Política de Colombia (1991): Se pretende la consolidación de la participación integral de los ciudadanos en un Estado Social de Derecho, en el nuevo proyecto de región - nación colombiana.

En el caso de la subregión del Canal del Dique, su cultura popular sirve de fuente pedagógica, lo que enriquece a los currículos, tal como lo plantea la Constitución Política de Colombia de (1991), la Ley General de la Educación (ley 115 de 1994), la Ley General de la Cultura (ley 397 de 1997). En sus apartes legales que reflexiona a la educación colombiana sobre la identidad en los procesos integrales, el desarrollo humano, la cultura, las comunidades, el sentido del arte local, regional y del proyecto histórico de nación.

\section{Logros alcanzados}

La responsabilidad de adelantar este tipo de estudio nos compromete a desmitificar en parte la historia del zambaje colombiano en una subregión habitada mayoritariamente por el legado sociocultural de comunidades negras, conocidas como pueblos "palenques", lo cual nos obliga hacer tránsito crítico reflexivo sobre la historia de la colonización (Bell Lemus, 1991). En consecuencia, los estudios realizados y sistematizados a través del grupo de investigación de la Universidad del Atlántico: Música-Cultura y Tradición y por la Corporación para la Investigación Etnomusical Son de Negro, han logrado en parte documentar las experiencias investigadas sobre esta cultura de la tradición, estudios hoy reguardado en el centro de Acopio Son de Negro, de esta forma se ha venido conociendo la veracidad de esta danza y música ancestral llena de múltiples lenguajes y que hace su aparición a finales del siglo XIX, en la región del Canal del Dique. Por eso la importancia de conocer la historia y evolución, como a personajes - hacedores - artistas - tipos de música - de danza - bailes - coreografía - literatura popular - la oralidad, y demás manifestaciones propias de esta manifestación artística. Por lo anterior, se es consciente del compromiso inaplazable que tienen los docentes transformadores de sus prácticas, como las instituciones educativas para que se den a la tarea de regular los currículos locales y regionales en el Caribe, y profundizar en estudios como el que se presenta que busca dar cuenta de la conformación de las comunidades negras en conflicto y/o negros cimarrones que se establecieron a mediados del siglo XVI, en las márgenes 
del bajo Magdalena.

Lo que Mosquera, (2002, pág. 33), “En plena época del cimarronismo (revolución o movimientos negreros, en 1633), se tiene indicio de la forma como se constituyeron los llamados palenques en diversas regiones de Colombia", no obstante los palenques que se establecieron en la subregión objeto de estudio fueron dirigidos por Reina Leonor; y estas comunidades negreras se asentaron posteriormente en las montañas de María, hoy montes de María la Alta y María la Baja, y sus áreas de influencia, tales como: El Betancur y Matudere en la sierra de Luruaco, la serranía de Piojó, El San Benito de las Palomas (antigua ciénaga de Repelón - Atlántico), El Limón y El Sanaguare, asentados en lo que hoy se conoce como el sur del Departamento del Atlántico, entre otros.

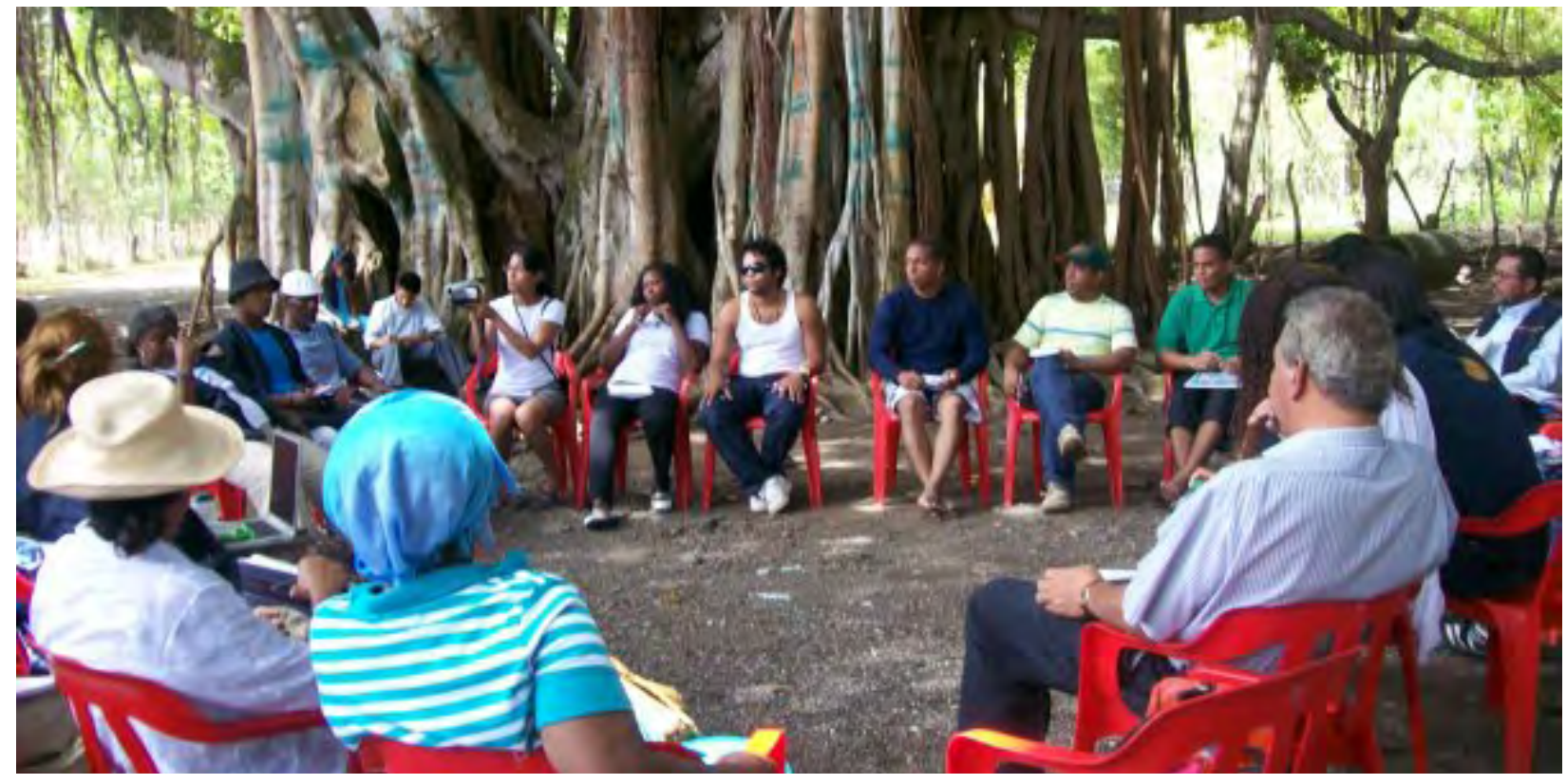

Imagen $\mathrm{N}^{\circ}$ 3. Trabajo de rutas de aprendizaje con comunidad afro (Fotografía archivo Rutas de Aprendizaje, 2017).

En lo relacionado a la danza Son de Negro, esta es visionada y comprendida como un compendio de múltiples lenguajes, espacios, personajes e imaginarios con sentido mágico religioso y desde principio de aparición en las localidades, formó parte de los rituales de las fiestas de cabildo abierto en las regiones del bajo Magdalena (Pérez, 2006), la expresión artística presenta diversidades de bailes, ritmos, tonadas y representaciones musicales que se conjugan con elementos visuales y plásticos tales como el tinte de color negro intenso que preparan los mismos participante de la danza con aceite de cocina y polvo mineral, y, que llevan untado en sus cuerpos los negros danzantes, ritual con el cual le dicen al universo cultural que se está exponiendo una manifestación netamente negroide (Pérez, 2006, pág. 13). En la danza se visibilizan tres (3) categorías, las cuales se desarrolla así:

Primera categoría Danza Teatral, especie de teatro libre con el ritual vistoso propio de la danza 
conocido como "Juego de Son de Negro", en esta parte se da un juego ceremonial con movimientos dancístico llenos de gesticulación facial, expresión estética-corporal, exagerados movimientos con bruscos movimientos con levante de glúteos y la realización de figuras como caminos culebreros, filas de cuadrillas, rondas y bailes recreativos acompañado del ritmo de llamado con la canción la rama del tamarindo. En este juego de Son de Negro, los danzarines realizan escenas de coqueteos a sus mujeres acompañantes con galanteos de juegos de ojos, labios y abertura de la boca mostrando la blancura de sus dentaduras y gestos de risas satíricas, además que los danzantes llevan algún animal disecados en la boca.

Segunda categoría Danza Guerrera, su mayor caracteristica está en la escenificación que hacen sus danzantes quienes ritualizan las formas de pelear y defensa contra el enemigo igual que la representación de cazar animales feroces como el tigre, el león, el jaguar, y otros animales selváticos, por eso la consigna de ser una expresión de origen selvática. En esta parte se da el ritual de La Llegada o reposo, escena en la cual aflora la variedad de ritmos y bailes de Son de Negro que determinan la movilidad y velocidad de la ejecución dancística.

Tercera categoría Danza de Laboreo, su escenografía deja ver la manera como los danzarines realizan en sus escenas trabajos como la limpia o macaneo de sus parcelas, ellos ritualizan bailes agachados-pordebajero, el ritual de piquiña en el cuerpo por las pelusas que surgen de la vegetación y/o por picaduras de animales, al tiempo escenifican sus formas de pesca artesanal y de cómo lanzar las atarrayas en los embalses. Igualmente hacen las representación de como surcan la tierra para hacer la siembra con el uso de palancas, por otro lado, realizan la forma de afilar sus sables, la tala de la vegetación. Lo descrito en está categoría esta simbolizado en la multiplicidad de atuendos y accesorios propios del trabajo agrícola, pesquero y minero, elementos visibilizados en los ganchos, lanzas, sables, cabuyas, lienzos, atarrayas, etc. En consonancia con la caracterización tanto en la danza como en la música se logra conocer en la zona de influencia de esta manifestación siete (7) ritmos y bailes de denominación Son de Negro, catalogados así: Llamado de Son de Negro o Cabildo, Son Negro Sentao, Son Negro Congolés, Puya Son Negro, Son Negro Pordebajero, Son Negro Vulgaria y Son Negro Ritmo de Negrito. En el estudio se logra conocer algunas variantes que presenta Son de Negro en el Caribe colombiano, entre las cuales están: Porro Negro, Los Negros, Los Negritos, Danza de Negro, etc.

El marco de celebración de esta manifestación de la tradición, no tiene fecha en el calendario y como es danza de la cotidianidad, permanentemente está presente en la comunidad y coreomusicalmente desarrolla en tres momentos o versiones:

Primera Versión: Es el Preámbulo o Cabildo Abierto (iniciación a la fiesta) con recorrido de la danza por las calles de la población invitando a la comunidad a participar de la fiesta con Son de Negro, esta primera escena está acompañada del ritmo de llamado y la canción La rama de tamarindo (Himno de la Danza). 
Segunda Versión: La Llegada o Reposo, lugar donde se realiza el concierto Son de Negro, en esta parte se ejecutan todos los ritmos y bailes de Son de Negro, y, otras manifestaciones de la zona, como el bullerengue, el son de pajarito, maestranza, los ritmos de sexteto, entre otros.

Tercera Versión: Despedida Forzosa, finalización de la fiesta, en este escenario la Danza Son de Negro, se despide ejecutando y bailando al ritmo de la canción La rama del tamarindo y se despiden de la comunidad con un hasta pronto. En la danza los hombres calzan abarcas tres puntá o danzan descalzos, llevan un sombreo campesino adornado con múltiples colores, y al frente de la danza llevan una bandera de color rojo, lo que para ellos significa libertad; las mujeres visten faldas y blusas de colores estampados, se adornan el cabello con flores cayena y se calzan con sandalias, en síntesis, la danza contextualiza todo cuanto se produce en su cotidianidad.

La implementación del diseño Son de Negro tendrá en cuenta los siguientes aspectos:

- Propiciar la formación investigativa en los niños y jóvenes camino a la construcción de nuevos conocimiento.

- Sensibilizar y organizar a la comunidad para que participen activamente en todos los eventos del Son de Negro.

- Crear espacios locativos para la animación y el despliegue que se le debe dar a esta cultura ancestral.

- Propender por la preservación y divulgación del Son de Negro interactuando coherentemente con las distintas instituciones de la población, la región y la nación, para que se le dé el reconocimiento que se merece este género primitivo.

Estructura curricular del plan de estudios

\begin{tabular}{|c|c|c|c|c|c|}
\hline $\begin{array}{l}\text { Campo de } \\
\text { Formación }\end{array}$ & Ejes Temáticos & Taller 1 & Taller 11 & $\begin{array}{c}\text { Producción Artística } \\
\text { Talleres } 11\end{array}$ & $\begin{array}{c}\text { Periodos } \\
\text { año }\end{array}$ \\
\hline $\begin{array}{l}\text { Teoria social } \\
\text { La etnografia } \\
\text { Fuentes } \\
\text { documentales } y \\
\text { bibliograficas de } \\
\text { los bailes locales } \\
\text { y regionales. }\end{array}$ & $\begin{array}{l}\text { Historia del folclor local, } \\
\text { regional } y \text { nacional de } \\
\text { Colombia. } \\
\text { Estudio de la música de } \\
\text { las danzas de la Region } \\
\text { del Canal del Dique }\end{array}$ & $\begin{array}{l}\text { Elaboración de los } \\
\text { diferentes elementos } \\
\text { de las danzas de la } \\
\text { poblacion. } \\
\text { Ambientes rurales - } \\
\text { urbanos - comunitario s. }\end{array}$ & $\begin{array}{l}\text { Estudio } y \\
\text { aprendizaje } \\
\text { De las expresiones } \\
y \text { gestos presentes } \\
\text { en las danzas } \\
\text { Diversidades de } \\
\text { bailes folclóricos }\end{array}$ & $\begin{array}{l}\text { Práctica musical. } \\
\text { Montajes } \\
\text { coreograficos con } \\
\text { las distintas danzas } \\
\text { de denominacion } \\
\text { de Son de Negro. }\end{array}$ & $\begin{array}{l}\text { Febrero- } \\
\text { Marzo- } \\
\text { Abril }\end{array}$ \\
\hline $\begin{array}{l}\text { Pedagogia musical } \\
\text {-dancistica de la } \\
\text { cultura del Son } \\
\text { de Negro y sus } \\
\text { danzas de } \\
\text { denominación. }\end{array}$ & $\begin{array}{l}\text { Organologia: } \\
\text { instrumentos musicales } \\
\text { utilizados en los ritmos } \\
\text { de la danza del Son de }\end{array}$ & $\begin{array}{l}\text { Construcción de los } \\
\text { instrumentos utilizados } \\
\text { en la parte musical de } \\
\text { las danzas. }\end{array}$ & $\begin{array}{l}\text { Desarrollo de la } \\
\text { expresion } \\
\text { corporal, vocal } \\
y \text { auditiva de los } \\
\text { actores del Son } \\
\text { de Negro. }\end{array}$ & $\begin{array}{l}\text { Elaboración de } \\
\text { ensayos } y \\
\text { artículos con } \\
\text { la danza } y \\
\text { folclóricos de la } \\
\text { población. }\end{array}$ & $\begin{array}{c}\text { Mayo- } \\
\text { Junio- } \\
\text { Julio }\end{array}$ \\
\hline
\end{tabular}




\begin{tabular}{|c|c|c|c|c|c|}
\hline $\begin{array}{l}\text { Desarrollo de una } \\
\text { practica educativa } \\
y \text { pedagógica con } \\
\text { la tradición oral } \\
\text { del Son de Negro }\end{array}$ & $\begin{array}{l}\text { Procesos de aprendizaje } \\
y \text { produccion creativa } \\
\text { Son de Negro, Pajarito, } \\
\text { Bulgaria, maestranza, } \\
\text { sexteto, Bullerengue. }\end{array}$ & $\begin{array}{l}\text { Producción de materiales } \\
\text { didacticos para las } \\
\text { actividades } \\
\text { artisticas con el Son de } \\
\text { negro en los contextos } \\
\text { educativos y culturales. }\end{array}$ & $\begin{array}{l}\text { Representación de } \\
\text { los gestos enla } \\
\text { interpretación } \\
\text { de los bailes } \\
\text { folclóricos } \\
\text { mencionados. }\end{array}$ & $\begin{array}{l}\text { Escenografias } \\
y \text { montajes } \\
\text { con muestras } \\
\text { folclóricas } \\
\text { institucional }\end{array}$ & $\begin{array}{l}\text { Noviembre } \\
\text { Diciembre }\end{array}$ \\
\hline
\end{tabular}

Cuadro $\mathrm{N}^{\circ}$ 1. Proyección curricular de los campos de formación, ejes temáticos y los contenidos de los talleres formativos a orientar en el proceso educativo. (Elaboración propia).

\section{CONCLUSIÓN}

El diseño de integración busca generar en la comunidad educativa sentido de pertenencia sobre el significado que tienen para sus habitantes la cultura ancestral Son de Negro, por ende la importancia de este estudio que busca desde la formación investigativa sistematizar contenidos, prácticas, saberes, lenguajes artísticos, representaciones, símbolos, rituales y demás elementos de esta expresión con la cual se identifican sus moradores.

Es indispensable desarrollar procesos académicos e investigativos con los estudiantes en diversos grados de escolaridad. No obstante, se estará salvaguardando, consolidando y proyectando la danza y la música Son de Negro, aquí se parte del hecho, que la educación está en la obligación de contextualizar sus contenidos en el currículo y formar al docente para que asuma con responsabilidad los cambios que reclama la educación en el hoy, es decir la del profesional - educador comprometido.

Por otro lado, es de suma importancia que las entidades gubernamentales (Departamento y el Estado), inviertan los recursos necesarios para el sostenimiento, la gestión, administración y la animación cultural con esta expresión, en la cual participan la comunidad vulnerable, los niños, adolescentes, adultos, adultos mayores y la tercera edad, sin distingo de clase social, política o credo. Con la participación de estos organismos se estará garantizando el proyecto de vida de esta tradición y juntos avanzaremos al desarrollo del nuevo proyecto región-nación que se busca.

Los ritmos y la danza Son de Negro esparcidos por toda la Costa Caribe y su entronque con las comunidades del Canal del Dique, desde épocas primitivas, se constituyeron en canales de comunicación artística, de desarrollo social y familiar para sus contextos. Esta cultura específica representada por los actores del Canal del Dique, se desarrolla a través de la exposición de músicas, danzas, bailes, literatura oral, coreografías, parafernalias, accesorios, las melodías que adornan los versos compuestos libremente y los instrumentos musicales que en ella participan.

La importancia de conocer a través de la integración al currículo, la historia y evolución 
social del Son de Negro, y de cómo se dio el proceso de colonización en la cual se da el zambaje social del hombre negro que puebla la región del Canal del Dique desde el instante que pisa suelo americano desde épocas remotas, este tipo de investigación ayuda a los estudiantes a comprender como se marcó el hito evolutivo de los palenques o sociedades negras en conflicto, asentadas en la depresión del Canal del Dique, en los departamentos de Atlántico y Bolívar y otros pueblos del Bajo Magdalena, situación que generó un carácter de formación social, política, geográfica y cultural en la región del Caribe colombiano.

Como riesgo de desaparición de esta expresión enraizada, también se encuentra las múltiples fusiones rítmicas que desvirtúan el sentido de origen y forma de una música que corresponde a los llamados bailes "canta'o". Igualmente las deformaciones que sufre la danza cuando se le introducen elementos que rompen con su origen, y muchas veces estas alteraciones para muchos ensayistas folcloristas es lo que mal interpretan como moderno o contemporáneo.

Por todo lo anterior, las instituciones gubernamentales del Municipio de Santa Lucía - Atlántico, y la Gobernación del Atlántico, al igual que la Corporación para la Investigación Etnomusical Son de Negro, esta última entidad sin ánimo de lucro, desde siempre se ha dado a la tarea por investigar y presentar ante el concejo municipal la idea de institucionalización de la cátedra Son de Negro, fundamentada como una innovación curricular para todas las escuelas y colegios de la población.

Uno de los propósitos de integrar al currículo al Son de Negro, es que las nuevas generaciones conozcan y participen activamente de esta tradición de la cual ellos son partícipes de sus bailes, cantos e interpretación de los ritmos, en tal sentido, ahí esta la importancia de involúcrarlos en procesos de investigación y en la práctica pedagógica de sus elementos, y a partir de ahí lograr que ellos construyan nuevos saberes fundamentado en el estudio de esta cultura ancestral con la cual se identifican y como reconocimiento de este patrimonio cultural específico de toda una subregión y que tiene según la historia sus principios en los antiguos cabildos negros cartagenero de los siglos XII -XVIII.

En el momento se está en procura de reactivar el centro de acopio Son de Negro, con sede en Santa Lucía, Atlántico, espacio abierto al público en el cual se han realizado estudios de todo orden sobre esta manifestación, además que el material indagado, sistematizado y publicado, hoy por hoy se constituye en fuente de pedagogía y de desarrollo sociocultural y educativo. Todo esto con el fin de fortalecer mucho más a esta cultura ancestral.

La población beneficiada tiene la posibilidad de adquirir materiales didácticos como: textos, revistas, video, casetes, disco compacto (cd). Del mismo modo se les dará la oportunidad para que los artesanos de la población socialicen su producción artística en exposiciones de artesanías, 
pinturas alusivas al arte local y regional, tanto en las instituciones educativas como en el marco del festival Son de Negro que se realiza todos los años en Santa Lucía.

Para la transmisión artística social y cultural, se pretende integrar a los actores mayores para que nutran con su sabiduría popular a los currículos de las instituciones educativas, y de esta forma consolidar de manera integrativa los procesos de formación que se orienten a partir de los elementos de la cultura folclórica del contexto, logrando que la enseñanza-aprendizaje sea más gratificante.

\section{REFERENCIAS BIBLIOGRÁFICAS}

Bell Lemus, Gustavo (1991).Cartagena de Indias. De la Colonia a la República. Capítulo V. Colección Historia No. 3. Fundación Simón y Lola Guberek. Santa Fe de Bogotá,

Berger, P Y Luckmann, T (2006): La construcción social de la realidad. 1 a Edición. Buenos Aires: Amorrortu.

García Canclini, Néstor (1995). Consumidores y ciudadanos. Conflictos multiculturales de la globalización. Editorial Grijalbo. México.

Caride José Antonio (2005). Las fronteras de la pedagogía social. Perspectivas científica e histórica. Editorial Gedisa, S.A. Biblioteca de Educación, Pedagogía Social y Trabajo Social. Barcelona, España.

CEPAL-UNESCO, (1992); Educación y conocimiento: Eje de la transformación productiva con equidad, Santiago de Chile.

Constitución Política de Colombia (1991); Art. 1 Art. 67. Asamblea Nacional Constituyente, Santafé de Bogotá, D.C.

Ley General de la Educación: Ley 115 de febrero 8 (1994). Editorial Unión. Bogotá, D.C. Colombia.

Ley 30 de Educación Superior (1992). Editorial Unión. Bogotá, D.C. Colombia.

Ley General de la Cultura, 379 de agosto 7 (1997). Ministerio de Cultura. Bogotá, D.C.

López Jiménez, Nelson Ernesto (2002); Retos para la construcción curricular. De la certeza al paradigma de la incertidumbre creativa. Editorial: Cooperativa Editorial Magisterio, Bogotá, Colombia.

López (2002, en Magendzo, 1991). Programa interdisciplinario de investigación en educación, PIIE. Ministerio de Educación, Bogotá, Colombia. 
Magendzo, Abraham (1996). Currículum, educación para la democracia en la modernidad. Instituto para el Desarrollo de la Democracia Luis Carlos Galán. Santafé de Bogotá D.C.

Mosquera Mosquera, Juan de Dios (2002). Las comunidades negras en Colombia. Fundación Color de Colombia.

Ortega \& Gasset, J. (1972): El hombre y la gente. Espasa- Calpe, Madrid, España.

Ortega \& Gasset, En Gutiérrez Constantino (2003). Conferencia: Historia integral de las artes. Universidad del Atlántico, Barranquilla.

Pérez Herrera, Manuel Antonio (2006). Tesis de Maestría Integración de la música como eje transversal de las estructuras curriculares del programa académico de educación artística, Universidad del Atlántico. Universidad del Norte, Barranquilla.

Pérez Herrera, Manuel Antonio (2006). La música Son de Negro y Son de Pajarito, punto de convergencia de la cultura tradicional y la oralidad de las comunidades del Bajo Magdalena. Revista El Artista N³, Universidad de Pamplona, Tunja, Boyacá.

Pérez Herrera, Manuel Antonio (2009). La educación artística musical para la construcción de competencias ciudadanas. Crecemos: Revista Hispanoamericana de Desarrollo Humano y Pensamiento. San Juan, Puerto Rico- XI, Nº 1,2 .

Pérez Herrera, Manuel Antonio (2009). Integración del conocimiento de la música: una perspectiva didáctica constructivista". Revista Latinoamericana de Estudios Educativos ISSN: 19009895 edición: Universidad de Caldas, Manizales.

Pérez Herrera, Manuel Antonio (2010). La práctica pedagógica investigativa: Nuevo rol de una educación Integral: Revista Horizontes Pedagógicos Volumen $12 \mathrm{~N}^{\circ} 1$. ISSN: 0123-8264. Iberoamericana Institución Universitaria. Publicación Facultad de Educación. Bogotá D.C. Colombia (enero-diciembre 2010).

Pérez Herrera, Manuel Antonio (2012). Tesis doctoral: Integración de la música a las estructuras curriculares de los programas artístico musical en la Universidad del Atlántico. Universidad de Caldas, Manizales - Rudecolombia.

PérezHerrera, Manuel Antonio (2016). Currículum transversal en la contemporaneidad. Universidad Autónoma del Caribe. Revista Escenarios. Open Journal Systems• Vol. 14, No. Enero-junio de 2016, págs. 85 -101. ISSN: 1794-1180. 
Quintana, José María. (1976): “Pedagogía social y sociología de la educación, I: Análisis comparativo de ambos conceptos y sus analogías”. Perspectivas Pedagógicas, N³7-38.

Stenhouse L (1997). Investigación y desarrollo curricular. Ediciones Morata. Madrid.

UNESCO, (2017). Prioridades de la UNESCO, promover la diversidad cultural, el diálogo intercultural y una cultura de paz. Disponible en:http://www.unesco.org/new/es/unesco/about-us/ who-we-are/introducing-unesco/ [Fecha de consulta: 14 de septiembre de 2017].

Vygotsky, (1979) El desarrollo de los procesos psicológicos superiores. Barcelona: Crítica. 